\title{
Analysis of beam-column elements on non-homogeneous soil using the differential transformation method
}

Análisis de elementos viga-columna en suelos no-homogéneos usando el método de la transformada diferencial Juan S. Carvajal-Muñoz (iD)', Carlos A. Vega-Posada (1D', Julio C. Saldarriaga-Molina (D)'

${ }^{1}$ Departamento de Ingeniería Civil y Ambiental, Escuela de Ingeniería, Universidad de Antioquia, Calle 67 \# 53-108. A. A. 1226 Medellín, Colombia.

\section{CITE THIS ARTICLE AS:}

J. S. Carvajal, C. A. Vega and J.

C. Saldarriaga. "Analysis of beam-column elements on non-homogeneous soil using the differential transformation method, no. 103, pp. 67-76, Apr-Jun 2022. [Online].

Available: https:

//www.doi.org/10.17533/

udea.redin. 20210218

\section{ARTICLE INFO:}

Received: August 14, 2020

Accepted: February 16, 2021

Available online: February 16 , 2021

\section{KEYWORDS:}

Beam-column element; Mathematical analysis; Non-homogeneous soil; Soil Mechanics

Elemento viga-columna; Análisis matemático; Suelo nohomogéneo; Mecánica de Suelos
ABSTRACT: This paper describes an analytical approach to conduct an analysis of beam-column elements with generalized end-boundary conditions on a homogeneous or non-homogeneous Pasternak elastic foundation. The mathematical formulation utilized herein is that presented by the senior author in a recent work. The differential equation (DE) governing the behavior of the beam-column element is solved using the differential transformation method (DTM). The DTM offers practical advantages over other conventional approaches when solving the proposed structural model. The proposed formulation provides the flexibility to account for i) combined lateral and axial load at the ends of the element, ii) homogeneous or non-homogeneous soil, iii) Pasternak elastic foundation, and iv) an external arbitrary transverse load acting on the element. The effects of various slenderness ratios, pile-soil stiffness ratios, and classical and semirigid boundary conditions can be easily studied with the proposed formulation. Examples are presented to validate the accuracy of the model and its applicability over a wide range of analyses.

RESUMEN: Este artículo describe un método analítico para el análisis de elementos viga-columna con condiciones de borde generalizadas apoyadas en una fundación elástica Pasternak homogénea o no-homogénea. La formulación matemática utilizada en este documento es una presentada recientemente por el autor principal. La ecuación diferencial (ED) que gobierna el comportamiento del elemento viga-columna se resuelve utilizando el método de transformación diferencial (DTM). Para el modelo estructural propuesto, el DTM ofrece ventajas prácticas sobre otros métodos. La formulación propuesta proporciona la flexibilidad de tener en cuenta i) carga lateral y axial combinada en los extremos del elemento, ii) suelo homogéneo o no-homogéneo, iii) fundación elástica Pasternak, y iv) una carga transversal arbitraria externa que actúa a lo largo del elemento. Los efectos de varias relaciones de esbeltez, relaciones de rigidez y condiciones de borde clásicas e intermedias se pueden estudiar fácilmente con la formulación propuesta. Se presentan ejemplos para validar la precisión del modelo y su aplicabilidad en una amplia gama de análisis.

\section{Introduction}

The behavior of beam-column elements resting on elastic foundations has been a subject of great interest in the last century [e.g., 1-8]. It has practical applications in civil engineering and other related engineering fields.

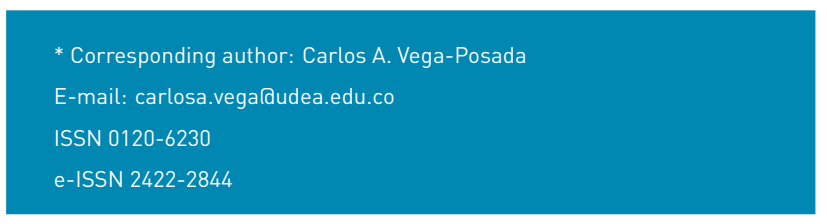

Winkler [1], one of the pioneers in the field, proposed to represent the soil as a series of closely spaced linear springs. This idealization, currently known as the Winkler approach, though practical, is a simplification of the soil medium because it neglects the shear interaction between the elements. To overcome this limitation, several authors have proposed the use of a two-parameter model, where the first parameter is analogous to the Winkler's spring and the second one represents a shear layer connecting the springs at the top ends [9-11]. Some models are derived to account for a uniform distribution 
of the modulus of subgrade reaction li.e., homogeneous soil). In this case, the DE governing the response of the element can be readily solved using classical approaches. However, when the soil parameter varies along the element (i.e., non-homogeneous soil), the DE has non-constant coefficients, and its solution becomes difficult. Thus, in some cases it cannot be solved analytically and a numerical solution needs to be provided. The DTM is used to solve the governing differential equation, and its corresponding boundary conditions. The DTM is a simple, efficient, and powerful method that converts differential equations into recursive algebraic expressions [e.g., 12-14]. The DTM was first implemented by Zhou [15] to solve electrical circuit problems, and it is a practical and powerfully approach to solve linear and non-linear differential equations. Some researchers have successfully employed the DTM to conduct static and dynamic analyses of beam-column elements [e.g., 16-22], but, in general, its application to civil engineering related problems is limited when compared to other fields.

The following conditions are incorporated in the proposed analysis: (a) a Pasternak two-parameter elastic foundation to account for the interaction between the springs; (b) an external transverse load acting on the element that fits a quadratic function. li.e., offers flexibility to consider uniformly distributed, trapezoidal or parabolic transverse loads); (c) any axial load, horizontal load and moment at each end of the element; and (d) semirigid connections and lateral restraints at the ends of the element. Both static and stability analyses can be conducted using the same set of equations, and the effects of any end-boundary condition on the element response can be studied without the need to discretize the solution for each individual boundary condition.

\section{Structural Model}

\subsection{Assumptions}

The proposed model considers a beam-column element $A^{\prime} B^{\prime}$ connected at both ends $A$ and $B$ as shown in Figure 1 by elastic springs $A A^{\prime}$ and $B B^{\prime}$ with flexural connectors $\kappa_{a}$ and $\kappa_{b}$ (units in force $\times$ distance/radian) and lateral springs $S_{a}$ and $S_{b}$ (units in force/distance). It is assumed that the beam-column $A^{\prime} B^{\prime}$ is: (1) prismatic with constant cross-sectional area, moment of inertia $I$ about the principal axis, and span $L ;(2)$ made of a linear elastic, homogeneous and isotropic material with elastic moduli $E$; (3) resting on a two-parameter elastic foundation, where the first parameter (i.e., $k_{s}$ ) can be either constant (homogeneous soil) or vary linearly with length or depth (non-homogeneous soil); and (4) subjected to an axial load $P$ (tension or compression), horizontal load $V$ and moment $M$ at its ends. It is assumed that all transverse deflections, rotations and strains along the beam are small so that the principle of superposition is applicable. For convenience, fixity factors parameters $\rho_{a}$ and $\rho_{b}$ are introduced. $\rho_{a}=1 /\left(1+(3 E I / L) / \kappa_{a}\right)$ and $\rho_{b}=1 /\left(1+(3 E I / L) / \kappa_{b}\right.$. These factors vary from zero (perfectly hinged connection) to one (clamped connection) [23].

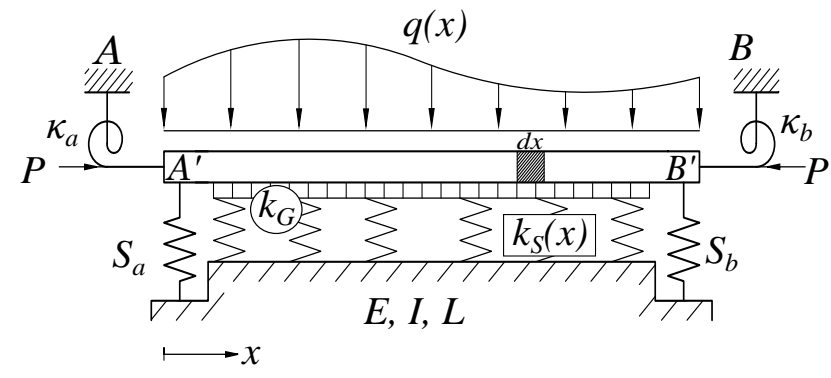

Figure 1 Proposed beam-column element.

\subsection{Governing Equations}

The governing DE of the beam-column element described in Figure 1 is obtained by applying equilibrium to the free-body diagram shown in Figure 2 [24]. The DE is described by Equation (1) as follows:

$$
E I \frac{d^{4} y}{d x^{4}}+P \frac{d^{2} y}{d x^{2}}+p(x)=q(x)
$$

where $p(x)=k_{s}(x) y-k_{G} \frac{d^{2} y}{d x^{2}}$ is the reaction normal to the element and $q(x)$ is an external transverse load that fits a second-degree polynomial function (i.e., $q(x)=a_{0}+a_{1} x+$ $a_{2} x^{2}$ ). $k_{s}(x)=k_{0}+c x$ is the modulus of subgrade reaction (first-parameter) and $k_{G}$ is the shear layer connecting the elements at the top ends (second-parameter). Introducing

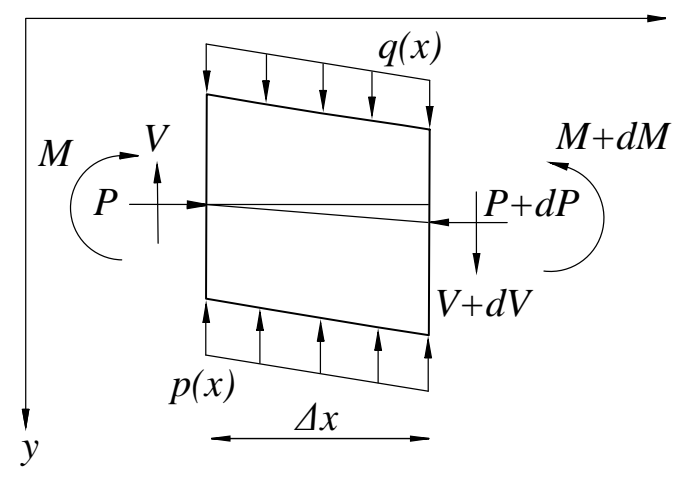

Figure 2 Free-body diagram of the differential element.

the non-dimensional expressions $\bar{x}=x / L$ and $\bar{y}=y / L$ into Equation (1) yields to Equation (2):

$$
\frac{d^{4} \bar{y}}{d \bar{x}^{4}}+F \frac{d^{2} \bar{y}}{d \bar{x}^{2}}+\Lambda(\bar{x}) \bar{y}=\Omega(\bar{x})
$$


where $F, \Lambda(\bar{x})$, and $\Omega(\bar{x})$ are given by Equations (3) - (5):

$$
\begin{gathered}
F=\frac{L^{2}}{E I}\left[P-k_{G}\right] \\
\Lambda(\bar{x})=\frac{L^{4}}{E I}\left[k_{0}+c L \bar{x}\right] \\
\Omega(\bar{x})=\frac{L^{3}}{E I}\left[a_{0}+a_{1} L \bar{x}+a_{2}(L \bar{x})^{2}\right]
\end{gathered}
$$

The boundary conditions at $\bar{x}=0$ are expressed by Equations (6a) - (6b):

$$
\begin{gathered}
M_{a}-\frac{3 E I \rho_{a}}{\left(1-\rho_{a}\right) L} \frac{d \bar{y}}{d \bar{x}}+\frac{E I}{L} \frac{d^{2} \bar{y}}{d \bar{x}^{2}}=0 \\
V_{a}-S_{a} L \bar{y}-\left(P-k_{G}\right) \frac{d \bar{y}}{d \bar{x}}-\frac{E I}{L^{2}} \frac{d^{3} \bar{y}}{d \bar{x}^{3}}=0
\end{gathered}
$$

and at $\bar{x}=1$ by Equations $(6 \mathrm{c})-(6 \mathrm{~d})$ :

$$
\begin{gathered}
M_{b}-\frac{3 E I \rho_{b}}{\left(1-\rho_{b}\right) L} \frac{d \bar{y}}{d \bar{x}}-\frac{E I}{L} \frac{d^{2} \bar{y}}{d \bar{x}^{2}}=0 \\
V_{b}-S_{b} L \bar{y}+\left(P+k_{G}\right) \frac{d \bar{y}}{d \bar{x}}+\frac{E I}{L^{2}} \frac{d^{3} \bar{y}}{d \bar{x}^{3}}=0
\end{gathered}
$$

where $V_{a}, V_{b}, M_{a}, M_{b}$ are the horizontal load and bending moment applied at ends A and B, respectively. Equation (2) is the normalized fourth-order linear differential equation with non-constant coefficients that describes the behavior of the proposed beam-column. Equations (6a)-(6d) are the corresponding boundary conditions of the DE.

\subsection{Differential transformation method}

The DTM is an analytical approach to solve differential equations. It is based on Taylor series, where the dependent variable is expressed as a series of infinite terms of the independent variable. The advantage of the DTM over other conventional approaches is that the problem is reduced to solve a system of two linear algebraic equations, which solution is easy to implement in a computational software or a personal calculator. Using conventional approaches, the mathematical formulation and solution of the proposed structural model becomes cumbersome and tedious to implement. The solution to the $D E$ is:

$$
\begin{aligned}
\bar{y}(\bar{x}) & =\bar{Y}(0)+\bar{Y}(1) \bar{x}+\bar{Y}(2) \bar{x}^{2}+\ldots+\bar{Y}(m) \bar{x}^{m} \\
& =\sum_{k=0}^{\infty} \bar{x}^{k} \bar{Y}(k)
\end{aligned}
$$

where $\bar{y}(\bar{x})$ is the original function (i.e., transverse deformation) and $\bar{Y}(k)$ is the transformed expression of the $k^{\text {th }}$ coefficient given by Equation (8).

$$
\bar{Y}(k)=\frac{1}{k !}\left[\frac{d^{k} \bar{y}(\bar{x})}{d \bar{x}^{k}}\right]_{\bar{x}=0}
$$

In practice, function $\bar{y}(\bar{x})$ in Equation (7) is expressed as a finite series of order $m$, so that $\bar{y}(\bar{x})=\sum_{k=m+1}^{\infty} \bar{x}^{k} \bar{Y}(k)$ is small.

Table 1 Some basic mathematical operations of DTM. [12]

\begin{tabular}{cl}
\hline Original function $y(x)$ & Transformed function $Y(k)$ \\
\hline$g(x) \pm h(x)$ & $G(k) \pm H(k)$ \\
$\alpha g(x)$ & $\alpha G(k)$ \\
$\frac{d^{n} g(x)}{d x^{n}}$ & $\frac{(k+n) !}{k !} G(k+n)$ \\
$g(x) h(x)$ & $\sum_{r=0}^{k} G(r) H(k-r)$ \\
$x^{n}$ & $\delta(k-n)$ \\
\hline
\end{tabular}

Substituting the transformed functions shown in Table 1 into Equation (2), the following recurring form of the $D E$ is obtained (see Equations (A1)-(A10) from appendix A) :

$$
\begin{aligned}
& \bar{Y}(k+4)= \\
& \begin{aligned}
{\left[\frac { L ^ { 3 } } { E I } \left[a_{0}\right.\right.} & \left.\delta(k)+a_{1} \delta(k-1) L+a_{2} \delta(k-2) L^{2}\right] \\
& -(k+2)(k+1) F \bar{Y}(k+2) \\
& \left.-\left[\Lambda_{0} \bar{Y}(k)+\Lambda_{1} \bar{Y}(k-1)\right]\right] / k_{4}
\end{aligned}
\end{aligned}
$$

where $k_{4}=(k+4)(k+3)(k+2)(k+1), \Lambda_{0}=k_{0} L^{4} / E I$ and $\Lambda_{1}=c L^{5} / E I$. Using Equation (7), the boundary conditions (i.e., Equations $(6 \mathrm{c})$ and $(6 \mathrm{~d}))$ are transformed as (see Equations (A12a)-(A12b) from appendix A):

$$
\begin{gathered}
\frac{M_{b}}{E I / L}-\frac{3 \rho_{b}}{\left(1-\rho_{b}\right)} \sum_{k=0}^{m} k \bar{Y}(k)-\sum_{k=0}^{m} k(k-1) \bar{Y}(k)=0 \\
\frac{V_{b}}{E I / L^{2}}-\frac{S_{b}}{E I / L^{3}} \sum_{k=0}^{m} \bar{Y}(k)+\frac{\left(P+k_{G}\right)}{E I / L^{2}} \sum_{k=0}^{m} k \bar{Y}(k) \\
+\sum_{k=0}^{m} k(k-1)(k-2) \bar{Y}(k)=0
\end{gathered}
$$

Equations (10) and (11) are a system of two linear algebraic equations in terms of $\bar{Y}(0)$ and $\bar{Y}(1)$ (i.e., deflection and rotation at $\bar{x}=0$ ). Terms $\bar{Y}(2)$ and $\bar{Y}(3)$ are found from Equations (A11a) and (A11b), respectively. The other terms, $\bar{Y}(4)-\bar{Y}(m)$, are found from the recurrence equation (Equation (9)). To solve the system, the values of $\bar{Y}(0)$ and $\bar{Y}(1)$ are initially assumed, and then the other terms of the series are determined. The intersection between these two lines is the solution $\bar{Y}(0)$ and $\bar{Y}(1)$ that satisfies both boundaries conditions (i.e., $\bar{x}=0$ and $\bar{x}=1$ ). Once the solution is known, coefficients $\bar{Y}(2)$ to 
$\bar{Y}(m)$ can be computed. The transverse deflection profile of the element is determined from Equation (7), the rotation from the first derivative of $\bar{Y}(\bar{x})$, and the shear force and bending moment profiles from:

$$
\begin{gathered}
V(\bar{x})=-\frac{E I}{L^{2}} \frac{d^{3} \bar{y}}{d \bar{x}^{3}}-P \frac{d \bar{y}}{d \bar{x}} \\
M(\bar{x})=-\frac{E I}{L} \frac{d^{2} \bar{y}}{d \bar{x}^{2}}
\end{gathered}
$$

\section{Comprehensive examples and verification}

Five examples are presented to validate the accuracy of the proposed approach. The results are compared with those obtained from other analytical approaches and finite element analyses in SAP2000 [25]. In SAP2000, beam elements were chosen to model the beam-column element and the shear deformations were ignored by equaling the shear rigidity to infinity.

Example 1: Beam-column resting on a Pasternak elastic foundation.

Determine the deflection, rotation, shear force, and bending moment profiles of the beam-column element resting on the Pasternak elastic foundation shown in Figure 3, and for the three different soil types listed in Table 2 li.e., dense sand, sand and gravel, and medium clayl. The beam-column element characteristics and soil types described in this example correspond to those presented by Arboleda-Monsalve et al.[26]. The beam is subjected to an axial compressive load and a trapezoidal transverse load as shown in Figure 3. Its assumed that $E_{p}=12 \mathrm{kN} / \mathrm{mm}^{2} ; I_{p}=5.208 \times 10^{9} \mathrm{~mm}^{4} ; L=6000$ $\mathrm{mm} ; \rho_{a}=0.7 ; \rho_{b}=0.3 ; S_{a}=15 \mathrm{kN} / \mathrm{mm} ; S_{b}=25$ $\mathrm{kN} / \mathrm{mm}$; and the external loads are: $q_{a}=0.4 \mathrm{kN} / \mathrm{mm}$; $q_{b}=0.2 \mathrm{kN} / \mathrm{mm} ; P=3000 \mathrm{kN}$. Figure 4 shows the

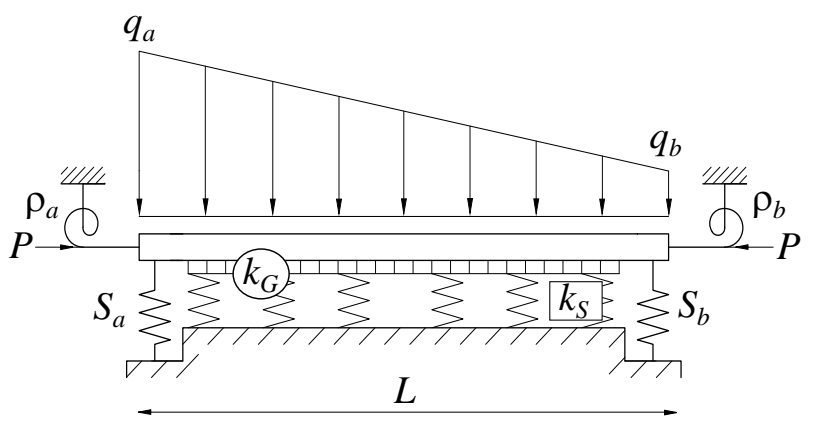

Figure 3 Beam-column under trapezoidal loading.

profiles of the vertical deflection, $y(x)$, rotation, $\theta(x)$, bending moment, $M(x)$, and shear force , $V(x)$, along the element. The results from the proposed approach are in excellent agreement with those obtained from SAP2000,
Table 2 Types of soils

\begin{tabular}{lll}
\hline Soil Type & $k_{S}\left(\mathrm{kN} / \mathrm{mm}^{2}\right)$ & $k_{G}(\mathrm{kN})$ \\
\hline Dense Sand & 0.0120 & 5425.19 \\
Sand and gravel & 0.0298 & 14680.94 \\
Medium clay & 0.0072 & 4989.08 \\
\hline
\end{tabular}

where the element was subdivided into 50 segments to provide sufficient accuracy.

Example 2: Second-order lateral stiffness of piles in non-homogeneous soil.

The variation of the pile lateral stiffness with changes in axial load and different distributions of the modulus of subgrade reaction $\left(k_{s}\right)$ is presented. Let $F=k_{0} / k_{l}$ be a non-dimensional term relating the modulus of subgrade reaction at $\bar{x}=0$ and $\bar{x}=1$. Then, $F=1$ represents a homogeneous soil (uniform distribution) and $F \neq 1$ a non-homogeneous soil (linear distribution). Although any end-boundary condition maybe analyzed with the proposed formulation, for the sake of brevity, only piles free at the bottom and rotational inhibited at the top $\left(\rho_{a}=1\right)$ are investigated. This condition is encountered in practice in the analysis of pile-supported wharves and piers [27].

The lateral stiffness index is defined as $s_{\delta}=S_{\Delta} L^{3} / E I$, where $S_{\Delta}=V_{a} / \Delta_{a}$ is the lateral stiffness of the pile. The axial load and lateral stiffness indices are defined as $N=$ $P L^{2} / 2 E I$ and $D_{s}=k_{l} L^{4} / E I$, respectively. The lateral stiffness, $S_{\Delta}$, associated to each axial load is computed by imposing a horizontal unit load $\left(V_{a}=1\right)$ and determining the transverse displacement at the top of the element.

Figure 5 shows the results from the parametric study. It is noted that, $s_{\delta}$ is the greatest for the uniform distribution of $k_{s}$ and the lowest for the linear triangular distribution. This highlights the importance of the upper portion of the soil on the pile lateral stiffness. When $F=1$ and $F=0.5, s_{\delta}$ decreases linearly as the axial load increases, and it drops almost to zero when the axial load approaches to the critical load. For the case when $F=0$ li.e., linear variation of $k_{s}$ ) the variation of $s_{\delta}$ is almost linear over the whole range of axial loads. The results are in agreement with those obtained from SAP2000 (for $F=1$ ).

Example 3: Bending moment profile of a laterally loaded pile. The proposed method captures the complete normalized bending moment profile of laterally loaded piles. The results are compared with those obtained from the numerical approach proposed by Banerjee and Davies [28]. The pile has a slenderness ratio of $L / B=25$, and it is fully embedded in homogeneous or non-homogeneous soil represented by values of $F=1, F=0.5$, and $F=0$. The analysis was conducted for a free-free pile. Banerjee and Davies [28] defined the non-dimensional expression for the relative pile flexibility ratio as $k_{r}=E_{p} I_{p} / E(L) L^{4}$. Note that $k_{r}=1 \times 10^{-1}$ corresponds to a very stiff pile li.e., 

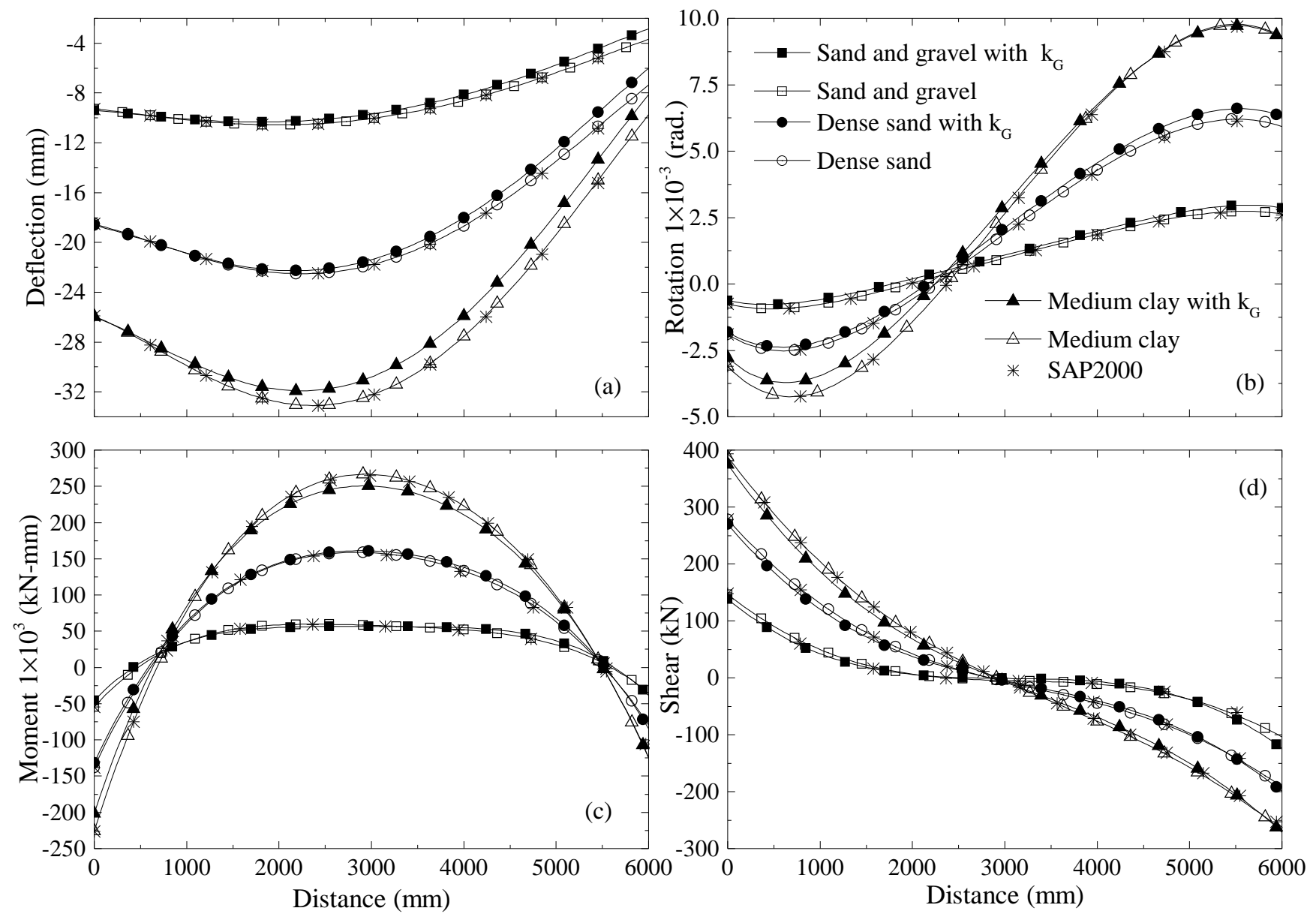

Figure 4 Example 1: (a) deflection; (b) rotation; (c) bending moment; (d) shear force of the beam-column element.

short pile) and $k_{r}=1 \times 10^{-4}$ to a flexible pile.

Figures 6 and 7 show, respectively, the normalized bending moment distribution of the pile when subjected to a horizontal load and a bending moment at the pile head. The results show that, regardless of the pile slenderness ratio, both the moment distribution and location of maximum moment are significantly affected by the variation of $k_{s}$. Overall, bending moments are greater in short piles than in flexible piles, and the magnitude decreases as $k_{s}$ moves from a linear triangular variation toward a uniform variation. The results are in good agreement with those reported by Banerjee and Davies [28] and computed with FE approaches (for the case of $F=1$ ).

Example 4: Lateral deflection of short and long piles.

When subjected to external lateral loads, short piles experience a rigid body translation and rotation, and therefore their response is influenced by both end-boundary conditions. On the other hand, long piles are those whose response is not influenced by the boundary condition at the base [29]. In general, a long pile is considered a pile with a slenderness ratio $(L / r>80)$. Piles with $L / r<80$ exhibit a transition from a flexible behavior toward a rigid one [30]. Pile slenderness ratio $(L / r)$ and relative stiffness ratio $\left(E_{p} / k_{s}\right)$ have a strong influence on the pile response. Here, some examples are reproduced from Basu and Salgado [31] to show this particular behavior. Figure 8 shows the deflection profile of a concrete short pile with radius $r=0.5 \mathrm{~m}$, Length $L=10 \mathrm{~m}$, and modulus of elasticity $E_{p}=2.4 \times 10^{6} \mathrm{kPa}$, fully embedded in a clay deposit with $k_{s}=11.6 \mathrm{MPa}$ and $k_{G}=6.8 M N$, and subjected to horizontal load of $100 \mathrm{kN}$ at the head. The pile is considered to be free at the head $\left(\rho_{a}=0\right.$ and $\left.S_{a}=0\right)$ and either free $\left(\rho_{b}=0\right.$ and $S_{b}=0$ ) or fixed $\left(\rho_{a}=1\right.$ and $S_{b}=\infty$ ) at the bottom. The results obtained from the proposed method and the method of initial parameters (MIP) developed by Basu and Salgado [31] show good agreement. Figure 9 shows the transverse deflection of a concrete pile with radius $r=0.25 \mathrm{~m}$ and lengths of $L=2.5 \mathrm{~m}, L=5 \mathrm{~m}$, and $L=6$ $\mathrm{m}$, embedded in a dense sand deposit with $k_{s}=130 \mathrm{MPa}$ and $k_{G}=7.9 \mathrm{MN}$, and subjected to a horizontal load of $100 \mathrm{kN}$ at the head. The pile is considered to be free at the head and either free or fixed at the bottom. The 2.5 $\mathrm{m}$ long pile shows that the base condition influences the deflection response. Meanwhile, the $5 \mathrm{~m}$ and $6 \mathrm{~m}$ long pile 

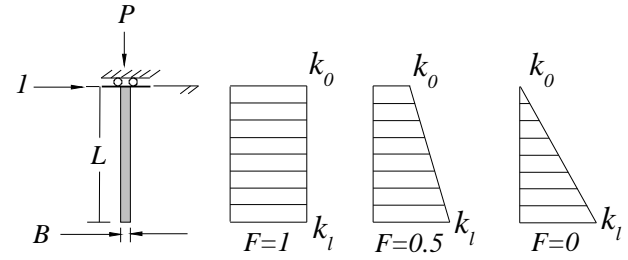

- $F=1 \quad$ (homogeneous)

- $F=0.5$ (non-homogeneous)

- $F=0 \quad$ (non-homogeneous)

$\Leftrightarrow \operatorname{SAP} 2000(F=1)$
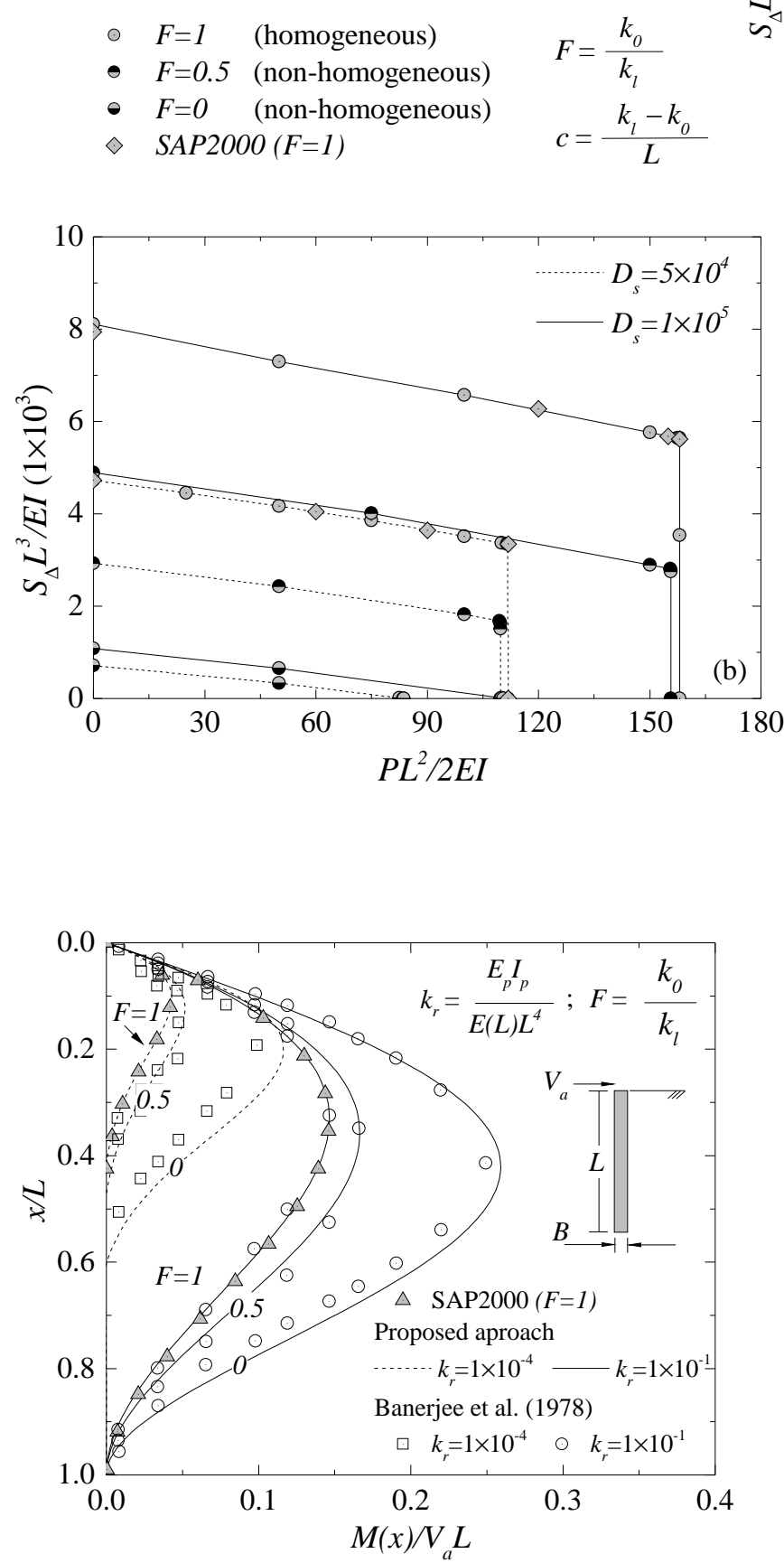

Figure 6 Moment distribution along the pile when subjected to a horizontal load.
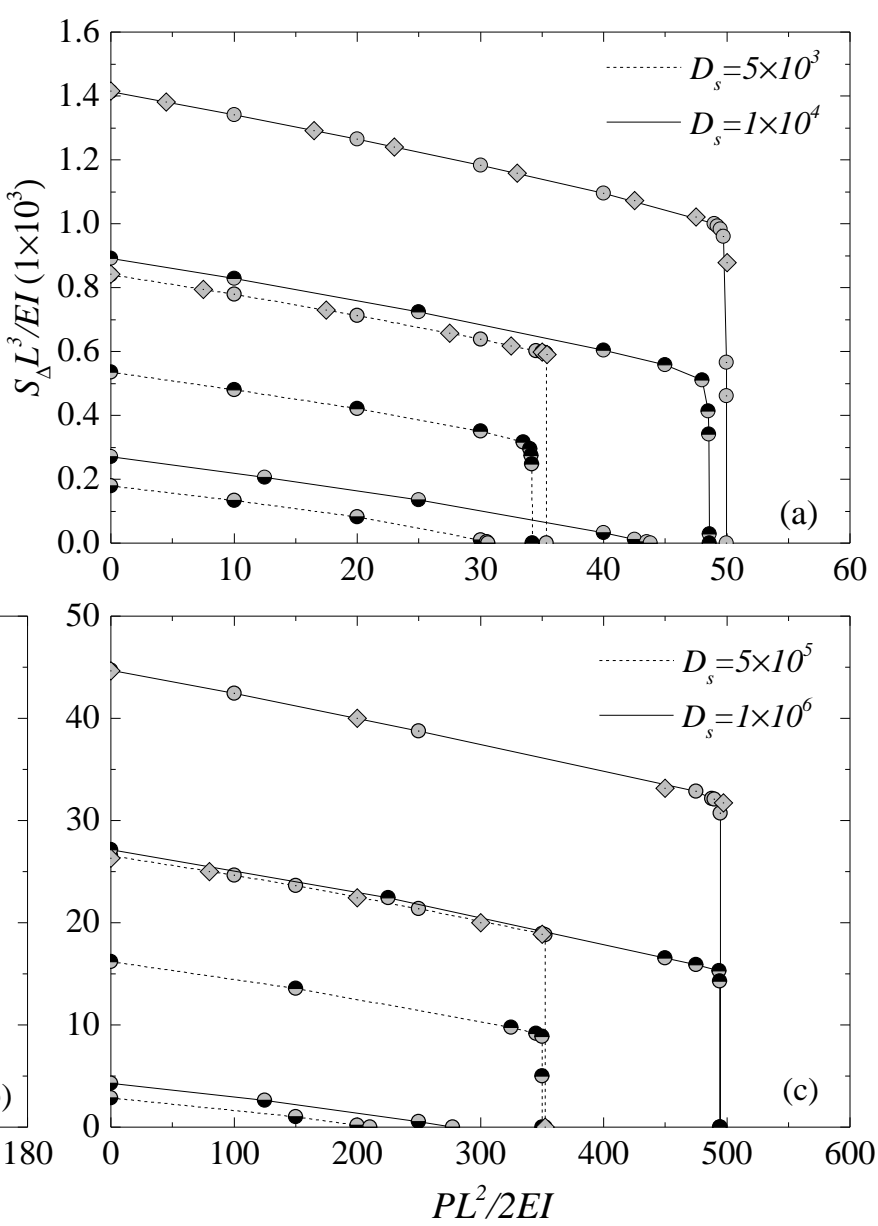

Figure 5 Example 2: Variation of the pile lateral stiffness.

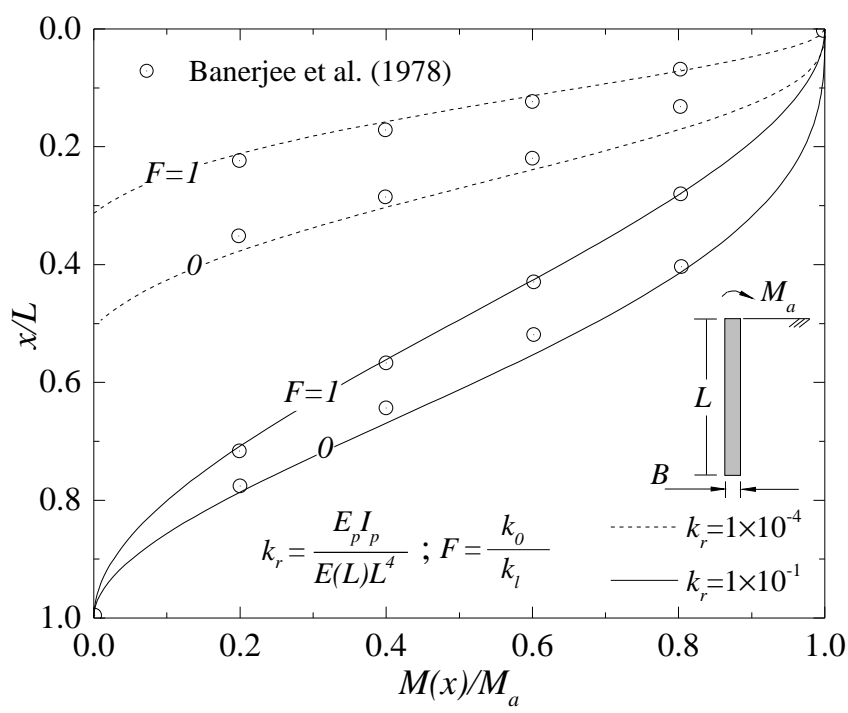

Figure 7 Moment distribution along the pile when subjected to a bending moment. 


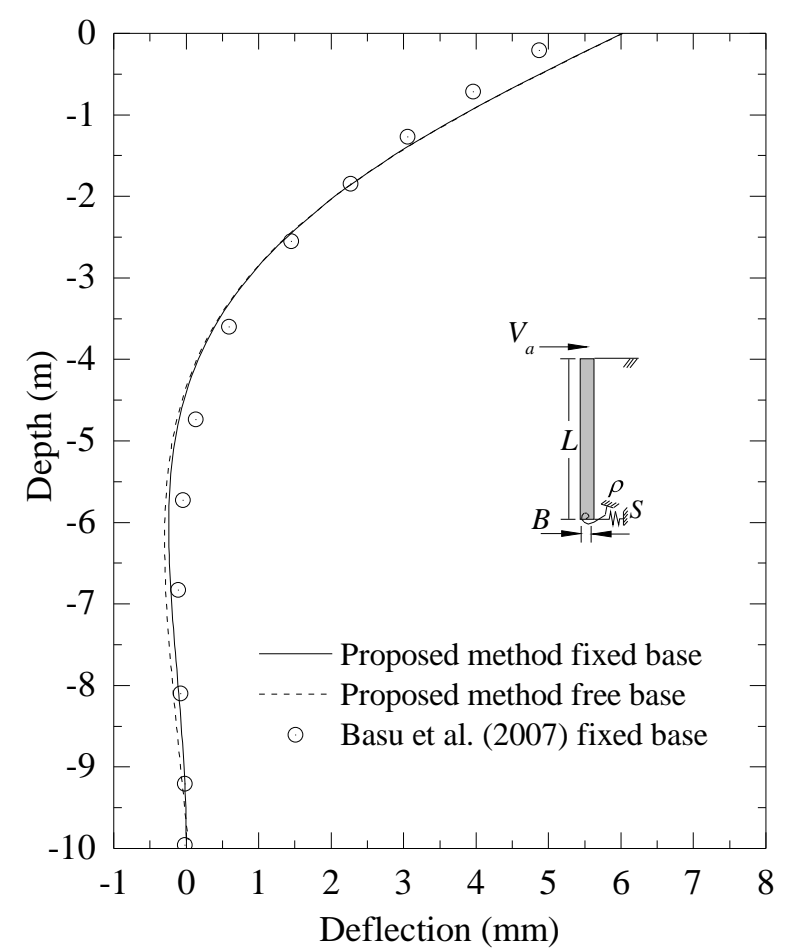

Figure 8 Deflection profile of a short pile embedded in clay.

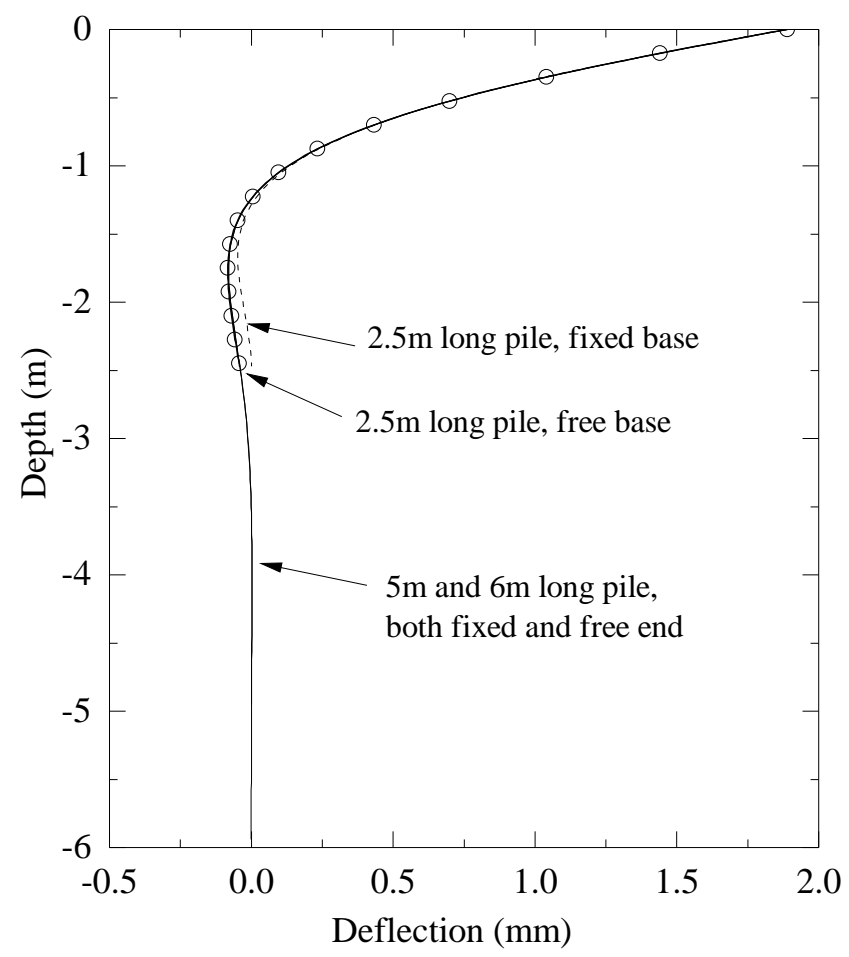

Figure 9 Deflection profile of a flexible pile embedded in dense sand.

have the same response for both free and fixed conditions.

Example 5: Normalized free-head pile displacement in homogeneous soil
Higgins et al. [30] used FEM analysis coupled with Fourier techniques to estimate lateral deflections and maximum moments of laterally loaded piles. Higgins et al. classified the pile depending on its relative stiffness $\left(E_{p} / k_{s}\right)$ and slenderness ratio $(L / r)$. A flexible long pile depends only on its relative stiffness, a flexible short pile on both relative stiffness and slenderness ratio, and a rigid pile only on its slenderness ratio. Figure 10 shows the normalized free-head pile deflection in homogeneous soil when the pile head is subjected to a horizontal load or bending moment. From this figure it is noted that, for flexible long piles, the head deflection decreases as the relative stiffness increases, and the decrements become less pronounced as the pile stiffness ratio increases. This response is more evident in piles with low values of soil stiffness ratios, where the lateral deflection becomes almost constant after a certain value of slenderness ratio.

\section{Conclusions}

A simple analytical approach to study the behavior of beam-column elements on homogeneous or non-homogeneous soil was presented and discussed. The fourth-order order DE with non-constant coefficients was solved using the differential transformation method (DTM). The solution to this DE using conventional approaches is rather complex. However, when the DTM is used, the resulting expressions consist of two linear algebraic equations which solution is easy to code in any computational software or spreadsheet. The same set of equations can be used to conduct either static or stability analyses of beam-column elements. The effects of various slenderness ratios, pile-soil stiffness ratios, and classical and semi-rigid boundary conditions can be easily studied with the proposed formulation. Five examples were presented to validate the accuracy and simplicity of the approach as well as its applicability over a wide range of practical applications. The results from the proposed model were in good agreement with those from FE analysis and other methods available in the technical literature.

As potential future studies, the proposed formulation can be extended to investigate i) the effect of an initial deformation on the beam-column response, b) cracked beam-columns by modeling the cracks as rotational springs, ii) static, elastic stability, and dynamic analysis of piles partially embedded in a multilayered soil by finding the static and dynamic stiffness matrices and corresponding loading vector, among others. 

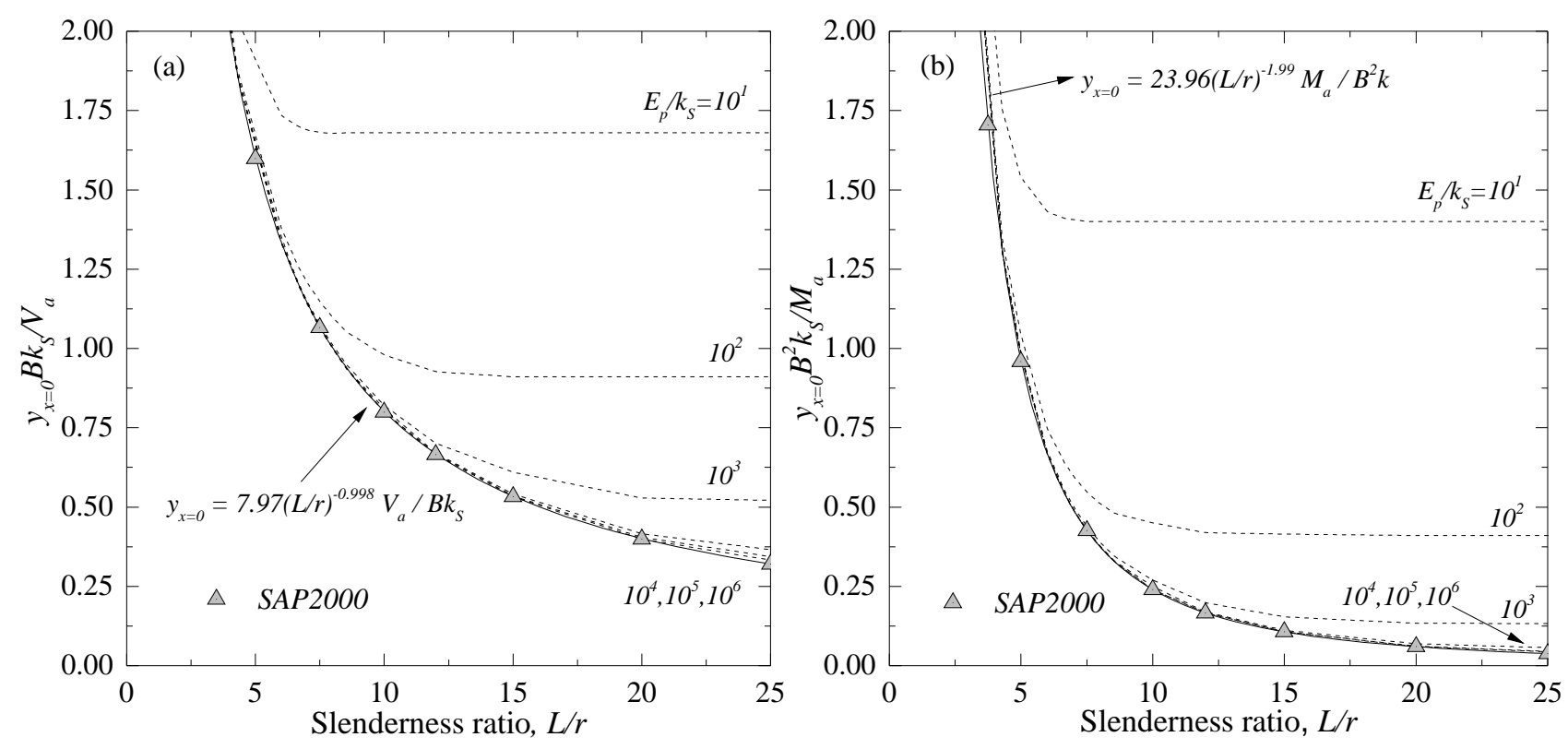

Figure 10 Pile-head lateral displacement vs. slenderness ratio for a pile subjected to (a) a horizontal force and (b) a bending moment at the head.

\section{Declaration of Competing Interests}

We declare that we have no significant competing interests including financial or non-financial, professional, or personal interests interfering with the full and objective presentation of the work described in this manuscript.

\section{Acknowledgment}

This research was carried out at the University of Antioquia, Medellín, Colombia. The support and suggestions of the Infrastructure Research Group (GII) of the University of Antioquia is appreciated. The authors are thankful to Claudia E. Urrego-Zapata for her help in checking for spelling and grammar.

\section{Appendix A. Transformation of the DE and B.Cs.}

The DTM is used to solve the DE governing the response of the proposed beam-column element (Equation (A1))

$$
\frac{d^{4} \bar{y}}{d \bar{x}^{4}}+F \frac{d^{2} \bar{y}}{d \bar{x}^{2}}+\Lambda(\bar{x}) \bar{y}=\Omega(\bar{x})
$$

Using properties from Table 1, Equation (A1) can be expressed in a recurrence form as Equation (A2) :

$$
\begin{gathered}
\bar{Y}(k+4)= \\
{[\bar{Q}(k)-(k+2)(k+1) F \bar{Y}(k+2)-} \\
\left.\sum_{r=0}^{k} \bar{\Lambda}(k-r) \bar{Y}(r)\right] / k_{4}
\end{gathered}
$$

where $k_{4}=(k+4)(k+3)(k+2)(k+1), \bar{\Lambda}(k), \bar{Q}(k)$ and $\bar{Y}(k)$ are the transformed functions of $\Lambda(\bar{x}), Q(\bar{x})$ and $\bar{y}(\bar{x})$, respectively. Note that $F=\frac{L^{2}}{E I}\left[P-k_{G}\right]$ and $\Lambda(\bar{x})=$ $\frac{L^{4}}{E I}\left[k_{0}+c L \bar{x}\right]$

$\bar{\Lambda}(k)$ and $\bar{Q}(k)$ are expressed in terms of the Dirac delta function as shown in Equations (A3a)-(A6) (using Table 1):

$$
\bar{\Lambda}(k)=\Lambda_{0} \delta(k)+\Lambda_{1} \delta(k-1)
$$

$$
\bar{Q}(k)=\frac{L^{3}}{E I}\left[a_{0} \delta(k)+a_{1} \delta(k-1) L+a_{2} \delta(k-2) L^{2}\right]
$$

substituting $k$ by $k-r$ in Equation (A3a) gives:

$$
\bar{\Lambda}(k-r)=\Lambda_{0} \delta(k-r)+\Lambda_{1} \delta(k-r-1)
$$

Substituting Equation (A4) into the expression $\sum_{r=0}^{k} \bar{\Lambda}(k-$ $r) \bar{Y}(r)$ in Equation (A2) gives: 


$$
\begin{aligned}
& \sum_{r=0}^{k} \bar{\Lambda}(k-r) \bar{Y}(r) \\
& =\Lambda_{0} \sum_{r=0}^{k} \delta(k-r) \bar{Y}(r)+\Lambda_{1} \sum_{r=0}^{k} \delta(k-r-1) \bar{Y}(r)
\end{aligned}
$$

Since $\delta(k-r)=1$ if $k=r$ or $\delta(k-r)=0$ if $k \neq r$, Equation (A5) is reduced to:

$$
\Lambda_{0} \bar{Y}(k)+\Lambda_{1} \bar{Y}(k-1)
$$

Now, substituting Equations (A3b) and (A6) into Equation (A2), the recurrence form of the differential equation is obtained (Equation 9).

For convenience, the first three terms of recurrence expression are presented (Equations (A7)-(A9)).

if $k=0$

$$
\bar{Y}(4)=\frac{L^{3} a_{0}}{24 E I}-\frac{F \bar{Y}(2)}{12}-\frac{\Lambda_{0} \bar{Y}(0)}{24}
$$

if $k=1$

$$
\bar{Y}(5)=\frac{L^{3}\left(a_{1} L\right)}{120 E I}-\frac{F \bar{Y}(3)}{20}-\frac{\Lambda_{0} \bar{Y}(1)+\Lambda_{1} \bar{Y}(0)}{120}
$$

if $k=2$

$$
\bar{Y}(6)=\frac{L^{3}\left(a_{2} L^{2}\right)}{360 E I}-\frac{F \bar{Y}(4)}{30}-\frac{\Lambda_{0} \bar{Y}(2)+\Lambda_{1} \bar{Y}(1)}{360}
$$

if $k \geq 3$

$$
\begin{aligned}
& \bar{Y}(k+4)= \\
& -\frac{F \bar{Y}(k+2)}{(k+4)(k+3)}-\frac{\Lambda_{0} \bar{Y}(k)+\Lambda_{1} \bar{Y}(k-1)}{(k+4)(k+3)(k+2)(k+1)}
\end{aligned}
$$

where, $\Lambda_{0}=k_{0} L^{4} / E I$ and $\Lambda_{1}=c L^{5} / E I$

The boundary conditions at $\bar{x}=0$ in terms of the DTM are (Equations (A11a)-(A11b)):

$$
\begin{gathered}
\frac{M_{a}}{E I / L}-\frac{3 \rho_{a}}{\left(1-\rho_{a}\right)} \bar{Y}(1)+2 \bar{Y}(2)=0 \quad \text { (A11a) } \\
\frac{V_{a}}{E I / L^{2}}-\frac{S_{a}}{E I / L^{3}} \bar{Y}(0)-\frac{\left(P-k_{G}\right)}{E I / L^{2}} \bar{Y}(1)-6 \bar{Y}(3)=0
\end{gathered}
$$

(A11b)

The boundary conditions at $\bar{x}=1$ in terms of the DTM are (Equations (A12a)-(A12b)):

$$
\frac{M_{b}}{E I / L}-\frac{3 \rho_{b}}{\left(1-\rho_{b}\right)} \sum_{k=0}^{m} k \bar{Y}(k)-\sum_{k=0}^{m} k(k-1) \bar{Y}(k)=0
$$

$$
\begin{gathered}
\frac{V_{b}}{E I / L^{2}}-\frac{S_{b}}{E I / L^{3}} \sum_{k=0}^{m} \bar{Y}(k)+\frac{\left(P+k_{G}\right)}{E I / L^{2}} \sum_{k=0}^{m} k \bar{Y}(k) \\
+\sum_{k=0}^{m} k(k-1)(k-2) \bar{Y}(k)=0
\end{gathered}
$$

(A12b)

\section{References}

[1] E. Winkler, Die Lehre von der Elastizitaet und Festigkeit. Prague: Dominicus, 1867.

[2] H. Zimmermann, Die Berechnung des Eisenbahnoberbaues, 2nd ed. Berlin: Ernst \& Korn, 1888.

[3] A. Dodge, "Influence Functions for Beams on Elastic Foundations," Journal of the Structural Division, vol. 90, no. 4, pp. 63-102, 1964.

[4] C. Miranda and K. Nair, "Finite Beams on Elastic Foundations," Journal of the Structural Division, vol. 92, no. 2, pp. 131-142, 1966.

[5] M. Hetenyi, "Beams on elastic foundation; theory with applications in the fields of civil and mechanical engineering," pp. ix, 255 p., 1946.

[6] K. Terzaghi, "Evaluation of coefficients of subgrade reaction," Geotechnique, vol. 5, no. 4, pp. 41-50, 1955.

[7] A.-M. L. G., Z.-M. D. G., and A.-O. J. Darío, "Reut and beck columns: effects of end gravity force, translation and rotational inertias," Revista Facultad de Ingeniería Universidad de Antioquia, no. 65, pp. 191-200, 2013. [Online]. Available: https://revistas.udea.edu.co/ index.php/ingenieria/article/view/14229

[8] J. D. Aristizabal-Ochoa, "Stability of slender columns on an elastic foundation with generalized end conditions," Ingeniería e Investigación, vol. 33, no. 3, pp. 34-40, 2013. [Online]. Available: https://revistas.unal.edu.co/index.php/ingeinv/article/view/41041

[9] P. L. Pasternak, On a New Method of Analysis of an Elastic Foundation by Means of Two Foundation Constants. Moscow: Gosudarstvennoe Izdatelstvo Literaturi po Stroitelstvui Arkhitekture, 1954.

[10] A. D. Kerr, "Elastic and Viscoelastic Foundation Models," Journal of Applied Mechanics, vol. 31, no. 3, pp. 491-498, 9 1964. [Online]. Available: https://asmedigitalcollection.asme.org/appliedmechanics/article/ 31/3/491/386992/Elastic-and-Viscoelastic-Foundation-Models

[11] V. Z. Vlasov and N. N. Leontev, Beams, plates and shells on elastic foundations. Jerusalem: Israel Program for Scientific Translations, 1966.

[12] I. H. Abdel-Halim Hassan, "Different applications for the differential transformation in the differential equations," Applied Mathematics and Computation, vol. 129, no. 2-3, pp. 183-201, 2002. [Online]. Available: https://doi.org/10.1016/S0096-3003(01)00037-6

[13] I. H. Abdel-Halim Hassan, "Application to differential transformation method for solving systems of differential equations," Applied Mathematical Modelling, vol. 32, no. 12, pp. 2552-2559, 2008. [Online]. Available: https://doi.org/10.1016/j.apm.2007.09.025

[14] C.-K. Chen and S.-H. Ho, "Application of differential transformation to eigenvalue problems," Applied Mathematics and Computation, vol. 79, no. 2-3, pp. 173-188, 10 1996. [Online]. Available: https://doi.org/10.1016/0096-3003(95)00253-7

[15] J. K. Zhou, "Differential transformation and its applications for electrical circuits," Wuhan, China, pp. 1279-1289, 1986.

[16] B. Bozyigit and Y. Yesilce, "Dynamic stiffness approach and differential transformation for free vibration analysis of a moving 
reddy-bickford beam," Structural Engineering and Mechanics, vol. 58 no. 5, pp. 847-868, 2016. [Online]. Available: https://doi.org/10. 12989/sem.2016.58.5.847

[17] B. Bozyigit, Y. Yesilce, and S. Catal, "Free vibrations of axial-loaded beams resting on viscoelastic foundation using adomian decomposition method and differential transformation," Engineering science and technology, an international journal, vol. 21, no. 6, pp. 1181-1193, 2018

[18] S. Çatal, "Buckling analysis of partially embedded pile in elastic soil using differential transform method," Structural Engineering and Mechanics, vol. 24, no. 2, pp. 247-268, 9 2006. [Online]. Available: https://doi.org/10.12989/sem.2006.24.2.247

[19] S. Catal, "Solution of free vibration equations of beam on elastic soil by using differential transform method," Applied Mathematical Modelling, vol. 32, no. 9, pp. 1744-1757, 2008. [Online]. Available: https://doi.org/10.1016/j.apm.2007.06.010

[20] Y. Yesilce, "Differential transform method for free vibration analysis of a moving beam," Structural Engineering and Mechanics, vol. 35, no. 5, pp. 645-658, 7 2010. [Online]. Available: https://doi.org/10. 12989/sem.2010.35.5.645

[21] M. Balkaya, M. O. Kaya, and A. Saglamer, "Analysis of the vibration of an elastic beam supported on elastic soil using the differential transform method," Archive of Applied Mechanics, vol. 79, no. 2, pp. 135-146, 2009. [Online]. Available: https: //doi.org/10.1007/s00419-008-0214-9

[22] B. Bozyigit, Y. Yesilce, and S. Catal, “Differential transform method and adomian decomposition method for free vibration analysis of fluid conveying timoshenko pipeline," Structural Engineering and Mechanics, vol. 62, no. 1, pp. 65-77, 2017. [Online]. Available: https://doi.org/10.12989/sem.2017.62.1.065

[23] J. D. Aristizabal-Ochoa, "First- and second-order stiffness matrices and load vector of beam-columns with semirigid connections," Journal of Structural Engineering, vol. 123, no. 5, pp. 669-678, 1997. [Online]. Available: https://doi.org/10.1061/(ASCE)0733-9445(1997)
123:5(669)

[24] C. A. Vega-Posada, A. P. Gallant, and M. Areiza-Hurtado, “Simple approach for analysis of beam-column elements on homogeneous and non-homogeneous elastic soil," Engineering Structures, vol. 221, p. 111110, 2020. [Online]. Available: https://doi.org/10.1016/j. engstruct.2020.111110

[25] S. v20.0.0., Computers \& Structures.INC, Walnut Creek, CA

[26] L. G. Arboleda-Monsalve, D. G. Zapata-Medina, and J. D. Aristizabal-Ochoa, "Timoshenko beam-column with generalized end conditions on elastic foundation: Dynamic-stiffness matrix and load vector," Journal of Sound and Vibration, vol. 310, no. 4-5, pp. 1057-1079, 2008. [Online]. Available: https: //doi.org/10.1016/j.jsv.2007.08.014

[27] A. F. Ramirez-Henao and J. Paul Smith-Pardo, "Elastic stability of pile-supported wharves and piers," Engineering Structures, vol. 97. pp. 140-151, 2015. [Online]. Available: https://doi.org/10.1016/j. engstruct.2015.04.007

[28] P. K. Banerjee and T. G. Davies, "The Behaviour of Axially and Laterally Loaded Sigle Piles Embedded In Non-Homogeneous Soils," Geotechnique, vol. 30, no. 1, pp. 88-92, 1980. [Online]. Available: https://doi.org/10.1680/geot.1980.30.1.88

[29] M. F. Randolph, "The response of flexible piles to lateral loading," Geotechnique, vol. 31, no. 2, pp. 247-259, 1981. [Online]. Available: https://doi.org/10.1680/geot.1981.31.2.247

[30] W. Higgins, C. Vasquez, D. Basu, and D. V. Griffiths, “Elastic solutions for laterally loaded piles," Journal of Geotechnical and Geoenvironmental Engineering, vol. 139, no. 7, pp. 1096-1103, 2013. [Online]. Available: https://doi.org/10.1061/(ASCE)GT.1943-5606. 0000828

[31] D. Basu and R. Salgado, "Method of initial parameters for laterally loaded piles embedded in layered soils," Geomechanics and Geoengineering, vol. 2, no. 4, pp. 281-294, 2007. [Online]. Available: https://doi.org/10.1080/17486020701678869 